\title{
Young Ichthyologist Award 2012 and Best Article Award 2012
}

The Ichthyological Society of Japan (ISJ) presented the Young Ichthyologist Award 2012 to Dr. Satoshi Awata (Niigata University) for his outstanding research activities on studying diverse mating strategies in fishes using an evolutionary- and behavioral-ecological approach. The Best Article Award 2012 was given to the following two papers.

Kano Y, Kawaguchi Y, Yamashita T, Shimatani Y (2010) Distribution of the oriental weatherloach, Misgurnus anguillicaudatus, in paddy fields and its implications for conservation in Sado Island, Japan. Ichthyological Research 57(2):180-188.

Takada M, Tachihara K, Nishida M (2010) Distribution and habitats of Carassius auratus in the Ryukyu Archipelago: comparisons between indigenous and introduced populations. Japanese Journal of Ichthyology 57(2):113-123.
Dr. Satoshi Awata gave a commemorative lecture entitled "Towards a deeper understanding of diverse mating strategies in fishes: an evolutionary- and behavioralecological approach', on 22 September 2012 during the ISJ annual meeting in Shimonoseki, Yamaguchi. He and the authors of the Best Article Award 2012 papers (Dr. Mikumi Takada of the University of Tokyo and Dr. Yuichi Kano of Kyushu University) received the commemorative certificates of merit from the ISJ President, Dr. Seishi Kimura. 